\title{
Calorimetric Study of N-methylacetamide in Polar and Non-Polar Solvents
}

\author{
Sabeeh Jalil Zaini \\ Department of Chemistry, College of Education Ibn-Al-Haithen, \\ University of Baghdad, Baghdad-Iraq.
}

\begin{abstract}
We have studied the dissolution of $\mathrm{N}$-methylacetamide in various solvents benzene, chloroform, acetone and water at $25^{\circ} \mathrm{C}$, has been observed through the study that the Enthalpy or dissociation varies from solvent to another and this is due to the formation of hydrogen bonding between solvent (self association) or between solute and solvent molecules. The study of this kind is commensurate with the change of the solvent mixture, whether polar or non-polar.
\end{abstract}

\section{Introduction}

As we examine this component spectrally or by (NMR) the amides are the most of all the carbonyl function groups, the results showed by many studies conducted within this area in respect of conduct double bond between carbon atom group carbonate and nitrogen atom with the result of the existence the probability of installation resonanece the cis and trans in relation to the site collection instance associated with nitrogen atom $[1,2]$. as well as an intermolecular of the molecule, one between the hydrogen atom associated with nitrogen atom and oxygen atom associated with the atom of carbon, and devoted several studies regarding by vibrations of the bond $\mathrm{N}-\mathrm{H}$ as well as bond $\mathrm{O}-\mathrm{H}$ in resonanece [3, 4] which showed by chapiro[5] there was no pack due to vibration of $\mathrm{O}-\mathrm{H}$ and this may inhence the probability of the type of resonanece $\mathrm{O}-\mathrm{H}$. In the process of intermolecular, some researchers have indicated [6,7] the fact that changes of composition for the copolymer are associated to the solvent user.

As we can see if we rotate the model, the carbon, and oxygen atoms, all lie in a plane (i.e.; all the carbon, nitrogen, and oxygen atoms lie on the same surface). Further the methyl groups $\left(-\mathrm{CH}_{3}\right)$ are trans to the $\mathrm{C}-\mathrm{N}$ bond (i.e.; they are on "opposite sides" of the $\mathrm{C}-\mathrm{N}$ bond). This is seen more dramatically if we change the display to a space-filling model showing van der waals radii.

The $\mathrm{C}-\mathrm{N}-\mathrm{C}$ bond angle is larger than expected from the simple Lewis and Vsepr models, as shown in the figures below:

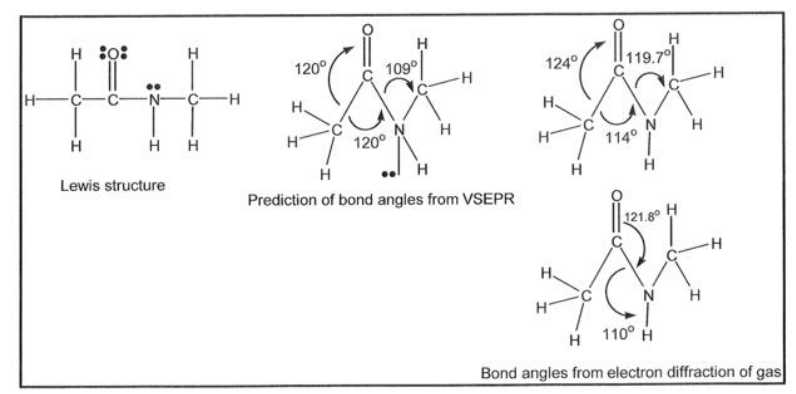

Fig. (1) Lewice and Vsepr model.

Additionally, the N-CO bond length is slightly shorter than the N-CH3 (138.6 pm versus $146.8 \mathrm{pm}$ ), while the simple Lewis model would predict similar $\mathrm{N}-\mathrm{C}$ bond lengths.

The planarity of the molecule, the $\mathrm{N}-\mathrm{C}=\mathrm{O}$ bond angle of $121.8^{\circ}$ (rather than the $109^{\circ}$ predicted from Vesper), and the shorter N-CO bond length are the justification for assuming these "resonace structures" for the amide [8]:

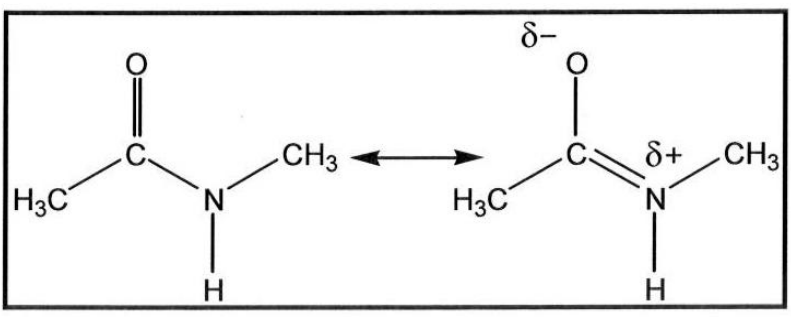

Fig.(2) Resonance structures of $\mathrm{N}$-methyacetamide.

In this research we obtained the enthalpies mixture of $\mathrm{N}$-methylacetamide with various solvents and the mixture is called enthalapies mixture of solute dissolved in a solvent. 


\section{Experimental Part}

The N- methylace mide was obtained from the company MERCK with purity $99 \%$ as well as other solvents like water-free ions were distilled three times, Either solvents acetone, benzene and chloroform were processed by the company OROLHBO that are used in devices spectrum spectroscopy, either thermal calorimeter is of type C. R.M. (SETARAM).

Monocells calorimeter is measured in terms of liberal fluxthermic as result of any interaction or physical phenomenon through the development of the thermal cell which surrounded by wire, as evident in Fig.(3).

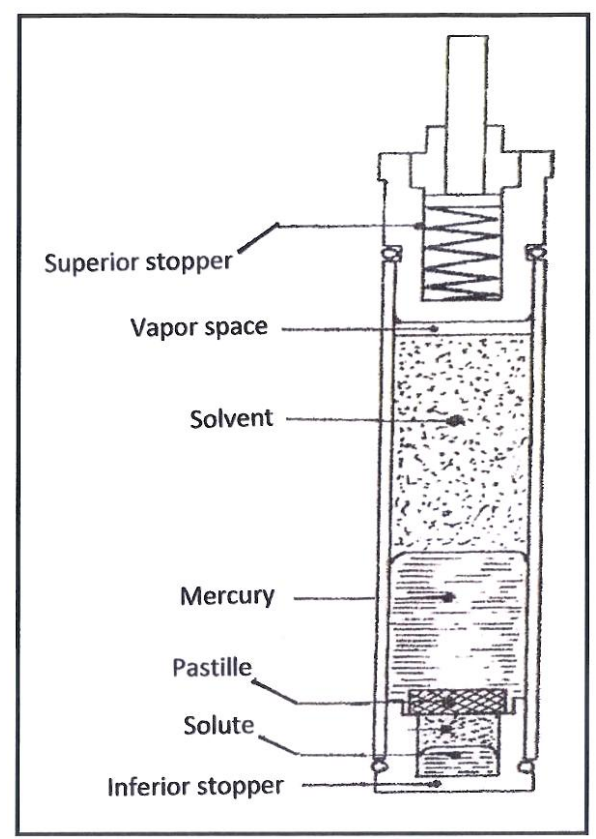

Fig. (3) Calorimetric cell.

To describe the amount of solute in different sizes placed on a disc of stainless steel about $4 \mathrm{~cm}^{3}$ of mercury, and then add to the mercury $4 \mathrm{~cm}^{3}$ of solvent and then leave the device for three hours turn it over and as a result we get thermal curves.

\section{Results and Discussion}

Our work based on the phenomena of self association by hydrogen bonding to determine the parameters of self association from calorimetric results. This method represents advantages for studying spectroscopy in this article, we presents the results concerning the dilute solutions (molality $<5 \times 10^{-2}$ ), from calorimetric measurements we permit determine the heat of solute in solvent, that heat of mixture which enable as to bring one mole of solute to obtain the molar enthalpy of dissolution $\Delta \mathrm{H}_{\mathrm{S}}$, the value of $\Delta \mathrm{H}_{\mathrm{s}}$ is a function of concentration in which the concentration being null towards the limit value of $\Delta \mathrm{H}_{\mathrm{s}}^{\circ}$ at infinity dilution.

The difference between $\Delta \mathrm{H}^{\circ}$ S and $\Delta \mathrm{H}_{\mathrm{S}}$ is characterized by $\varnothing_{\mathrm{L}}=\Delta \mathrm{H}^{\circ}{ }_{\mathrm{S}}-\Delta \mathrm{H}_{\mathrm{S}}$.

We consider $\mathrm{A}$ as a molecular component which is to form self association by linear aggregate.

This self association is characteristic by general equilibrium.

$\mathrm{A}_{\mathrm{i}-1}+\mathrm{A}_{1 \Leftrightarrow} \Leftrightarrow \mathrm{A}_{\mathrm{i}}$ and by corresponding constant $\mathrm{k}_{\mathrm{i}}=\frac{\left(\mathrm{A}_{\mathrm{i}}\right)}{\left(\mathrm{A}_{\mathrm{i}}-1\right)(\mathrm{A} 1)}$

If $\mathrm{m}$ is the stoechiometric molality, we can write : $m=\left(A_{1}\right)+2\left(A_{2}\right)+\ldots i\left(A_{i}\right)$.

where $\left(A_{i}\right)$ is the molaity of polymer of order $\mathrm{i}$, to calculate the constant and enthalpies of self association,

The parameter $m \varnothing_{\mathrm{L}}$ represents the variation of enthalpy due to dilution of $\mathrm{m}$ moles of solute which passes through solution of molality $\mathrm{m}$ to infinity dilute solution. If we assume the parameter $m \varnothing_{\mathrm{L}}$ express only the dissociation of component $\mathrm{A}_{\mathrm{i}}$, which means has broken hydrogen bonding, and then we can write the following equation:

$m \varnothing_{\mathrm{L}}=\left(\mathrm{A}_{2}\right)\left(\Delta \mathrm{H}_{2}\right)+\left(\mathrm{A}_{3}\right)\left(\Delta \mathrm{H}_{2}+\Delta \mathrm{H}_{3}\right)+\ldots+$ $\left(\mathrm{A}_{\mathrm{i}}\right)\left(\Delta \mathrm{H}_{\mathrm{i}}+\ldots+\Delta \mathrm{H}_{\mathrm{i}}\right)$.

the parameter $\Delta \mathrm{H}_{\mathrm{i}}$ corresponds to the following equilibrium.

$$
\begin{aligned}
& \mathrm{A}_{2} \leftrightarrow \mathrm{A}_{1}+\mathrm{A}_{1} \Delta \mathrm{H}_{2} \\
& \mathrm{~A}_{3} \leftrightarrow \mathrm{A}_{2}+\mathrm{A}_{1} \Delta \mathrm{H}_{3}
\end{aligned}
$$$$
\mathrm{A}_{\mathrm{i}} \leftrightarrow \mathrm{A}_{\mathrm{i}-1}+\mathrm{A}_{1} \Delta \mathrm{H}_{\mathrm{i}}
$$

If we suppose that the variation of enthalpy $\Delta \mathrm{H}_{\mathrm{i}}$ is the same for each step to break the polymer, then $\Delta \mathrm{H}_{2}=\Delta \mathrm{H}_{3}=\ldots \Delta \mathrm{H}_{\mathrm{i}}=\Delta \mathrm{H}$, hence

we can rewrite the equation (1) as follows:

$\phi_{1}=\Delta \mathrm{H} \frac{\left(\mathrm{A}_{2}\right)+2\left(\mathrm{~A}_{3}\right)+\ldots(\mathrm{i}-1)\left(\mathrm{A}_{\mathrm{i}}\right)}{\mathrm{m}}=\Delta \mathrm{H} \times \alpha$

where $\propto$ represents the amide mono substitute.

The percentage of $\mathrm{N}-\mathrm{H}$ bond which lies with $\mathrm{C}=\mathrm{O}$ in respect of total $\mathrm{N}-\mathrm{H}$ can be obtain the constants of self association from 
the calorimetric results, and then we can write the following equation:

$$
\lim _{\mathrm{m} \rightarrow \infty} \phi_{\mathrm{L}}=\Delta \mathrm{H}=\lim _{\mathrm{m} \rightarrow \infty}\left(\Delta \mathrm{H}_{\mathrm{s}}^{0}-\Delta \mathrm{H}_{\mathrm{s}}\right)=\Delta \mathrm{H}_{\mathrm{s}}^{0}-\lim _{\mathrm{m} \rightarrow \infty} \Delta \mathrm{H}_{\mathrm{s}}
$$

where $\Delta \mathrm{H}_{\mathrm{s}}$ is the molar dissolution enthalpy of solute which is function of partial molar enthalpies $\Delta \mathrm{H}_{\mathrm{s}}=\frac{\mathrm{n}_{1}}{\mathrm{n}_{2}} \Delta \mathrm{H}_{1}^{-}+\Delta \mathrm{H}_{2}^{-}$.

where 1 is relative to the solvent and 2 is relative to solute, and when $\mathrm{m}$ goes to infinity then $\mathrm{n}_{\mathrm{i}} \rightarrow 0$ and $\Delta \overline{\mathrm{H}}_{2}$ approaches to zero.

Hence $\lim _{\mathrm{m} \rightarrow \infty}=\Delta \mathrm{H}=0$

$$
\Delta \mathrm{H}=\Delta \mathrm{H}_{\mathrm{s}}^{0} \text {. }
$$

when the values of $\varnothing_{\mathrm{L}}$ and $\Delta \mathrm{H}_{1}$ are known we can determined the constant of dimirisation,

$$
\begin{aligned}
& \mathrm{K}_{2}=\lim _{\mathrm{m} \rightarrow \infty} \frac{\alpha}{1-\alpha} \cdot \frac{1}{\mathrm{~m}}=\lim _{\mathrm{m} \rightarrow \infty} \frac{\phi_{\mathrm{L}}}{\Delta \mathrm{H}-\phi_{\mathrm{L}}} \cdot \frac{1}{\mathrm{~m}} \\
& \mathrm{~K}_{2}=\lim _{\mathrm{m} \rightarrow \infty} \frac{\phi_{\mathrm{L}}}{\Delta \mathrm{H}-\phi_{\mathrm{L}}} \cdot \frac{1}{\mathrm{~m}} \ldots \ldots \ldots \ldots \ldots \ldots \ldots \ldots \ldots \ldots \ldots \ldots \ldots \ldots
\end{aligned}
$$

For one association of multi step (dimmer, trimer, ...), the successive different constants are equal.

$$
\left.\begin{array}{lc}
\mathrm{A}_{1}+\mathrm{A}_{1} \rightarrow \mathrm{A}_{2} & \mathrm{~K}_{2}=\frac{\left(\mathrm{A}_{2}\right)}{\left(\mathrm{A}_{1}\right)^{2}} \\
\mathrm{~A}_{2}+\mathrm{A}_{1} \rightarrow \mathrm{A}_{3} & \mathrm{~K}_{3}=\frac{\left(\mathrm{A}_{2}\right)}{\left(\mathrm{A}_{2}\right)\left(\mathrm{A}_{1}\right)} \\
\mathrm{A}_{\mathrm{i}-1}+\mathrm{A}_{1} \rightarrow \mathrm{A}_{\mathrm{i}} & \mathrm{K}_{\mathrm{i}}=\frac{\left(\mathrm{A}_{\mathrm{i}}\right)}{\left(\mathrm{A}_{\mathrm{i}-1}\right)\left(\mathrm{A}_{1}\right)}
\end{array}\right\}
$$

The stoechiometric molality can be written,

$$
\mathrm{m}=\left(\mathrm{A}_{1}\right)+2\left(\mathrm{H}_{2}\right)+\ldots \mathrm{i}\left(\mathrm{A}_{\mathrm{i}}\right)=\frac{\left(\mathrm{A}_{\mathrm{i}}\right)}{\left[1-\mathrm{K}\left(\mathrm{A}_{1}\right)\right]^{2}}
$$$$
\text { Hence } \phi_{\mathrm{L}}=\frac{\Delta \mathrm{H} \cdot \mathrm{K}}{\mathrm{M}} \cdot\left(\frac{\mathrm{A}_{1}}{1-\mathrm{K}\left(\mathrm{A}_{1}\right)}\right)^{2}
$$

For combination of the last two expressions results in :

$\phi_{\mathrm{L}}=\Delta \mathrm{H}-\left(\frac{\Delta \mathrm{H}}{\mathrm{K}}\right)^{\frac{1}{2}} \cdot\left(\frac{\phi_{\mathrm{L}}}{\mathrm{m}}\right)^{\frac{1}{2}}$

The variation of $\varnothing_{L}$ as a function of $\left(\frac{\phi_{\mathrm{L}}}{\mathrm{m}}\right)^{\frac{1}{2}}$ must be linear. the slope of straight line permit to determine $\Delta \mathrm{H}$ and $\mathrm{K}$. The role of solvent plays an important role in the process of solvation for the owned properties of physical and chemical means that the role of solvent physical properties like dielectric constant and dipolmoment are played an important role in the process of solvation, but when the use of solvent in this research that all solvents have a special role in the process to surround the molecule, $\mathrm{N}$ - methylacetamide the carbonyl or $\mathrm{N}-\mathrm{H}$ to form hydrogen bonding [9] it is known that an Amide linkage is kinetically stable to hydrolysis $[10,11]$. It can be Hydrolysed in boiling alkali, as well as in strong acidic conditions. Amid linkages in a biochemical context are called peptide linkages and it constitute a defining molecular feature of proteins. The secondary structure of which is due in part to the hydrogen bonding abilities of amides [12].

Amides are very weak bases. While the conjugate acid of an amide has $\mathrm{pKa}$ of about 9.5, the conjugate acid of an amide has a $\mathrm{pKa}$ around 0.5. therefore amides don't have has as clearly noticeable acid- base properties in water. this lack of basicity is explained by the electron- withdrawing nature of the carbonyl group where the lone pair of electrons on the nitrogen is delocalized by resonancy, thus forming a partial double bond with the carbonyl carbon and putting a negative charge on the oxygen. On the other hand, amides are much stronger bases than carboxylic acids, esters, aldehydes, and ketones (conjugated acid pKa between -6 and -10). It is estimated in silico that acetamide and by $\mathrm{B}$ for 28 percent [13]. Resonance is largely prevented in the very strained quinuclidone.

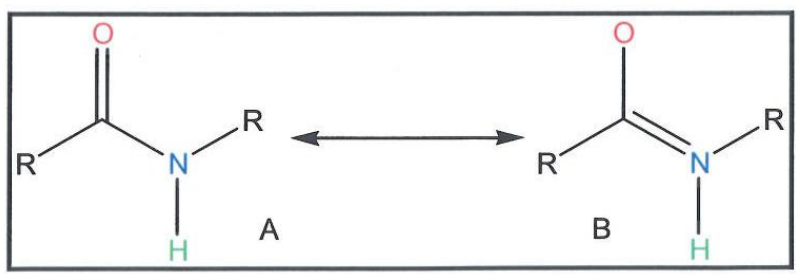

Fig.(4) N-methylacetamide resonance.

Amides contain carbonyl $(\mathrm{C}=\mathrm{O})$ and ether $(\mathrm{N}-\mathrm{C})$ dipoles arising from covalent bonding between electronegative oxygen and nitrogen atoms. Primary and secondary amides also contain two- and one N-H dipoles, 
respectively. Because of the pi-bonding arrangement of the carbonyl and the greater electronegativity of oxygen, the carbony $(\mathrm{C}=\mathrm{O})$ is a stronger dipole than the $\mathrm{N}-\mathrm{C}$ dipole. The presence of a $\mathrm{C}=\mathrm{O}$ dipole, allows amides to act as $\mathrm{H}$ - bond acceptors. In primary and secondary amides, the presence of $\mathrm{N}-\mathrm{H}$ dipoles allows amides to function as H-bond donors as well. Thus amides can participate in hydrogen bonding with water and other protic solvents; the oxygen and nitrogen atoms can accept hydrogen bonds from water and the N-H hydrogen atoms can donate $\mathrm{H}$ - bonds. As a result of interactions such as these, the water solubility of amides is greater than of corresponding hydrocarbons.

While hydrogen bonding may enhance the water solubility of amides relative to hydrocarbons (alkanes, alkenes, alkynes and aromatic compounds), amides typically are regarded as compounds with low water solubility. They are significantly less water soluble than comparable acids or alcohol the presence of nonpolar hydrocarbon functionality the inability of tertiary amides to donate hydrogen bonds to water (they can only be H-bond acceptors). Thus amides have water solubility roughly comparable to esters. Typically amides are less soluble than comparable to esters amines and carboxylic acids sinc these compounds can both donate and accept hydrogen bonds, and can ionize at appropriate $\mathrm{pHs}$ to further enhance solubility $[14,15]$.

In the case of the use of solvents such as benzene for example the solubility is less than the other and we can note that the value of the dissociate enthalpy is little in comparison with other solvents (Fig.(5)).

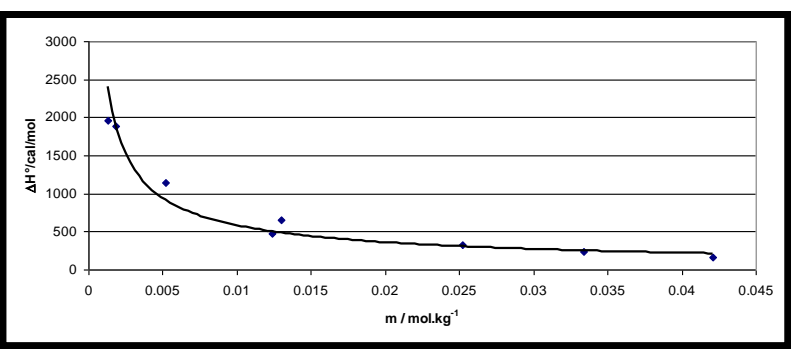

Fig.(5) System of benzene+ $N$ - methyacetamide.

The amide can be attributed to a monomar and on the basis of a difference in the process of two main factors, namely to break the
Association amide- amide endothermic and second configuration complexes of Amidesolvent which in turn causes by the enthalpy scaled back to two effects contrast a matter to neglect of interactions non- specific versus Principle effects [16-17].

Since chloroform is considered as a polar solvents we have found that interaction with the type of dipole- dipole this interaction is weak comparison with bonds amid- amid and this explains the decrease in the values of $\Delta H$ due to increase of solute concentration in the form of solvent Fig.(6).

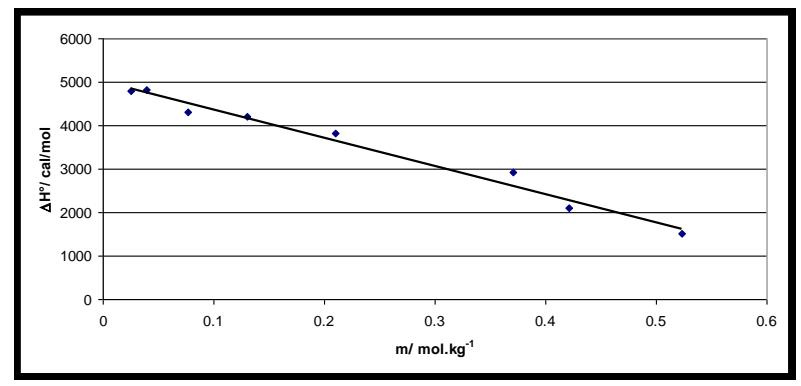

Fig.(6) System of chloroform$\mathrm{N}$-methyacetamide.

In the case of acetone the carbonyl group $\mathrm{C}=\mathrm{O}$ can be formed hydrogen bonding with acetamide proton we can observe that the value of enthalpy is high as in Fig.(7).

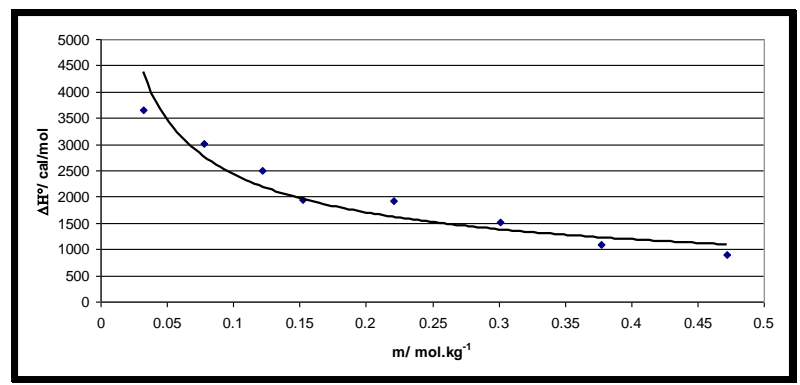

Fig. (7): System of acetone + $N$ - methyacetamide.

In the case of water we have found that the value of $\Delta \mathrm{H}$ is low, this solvent will complex with the solute due to forming hydrogen bonding between the proton of acetamide and oxygen atom of water and the other hand the oxygen of carbonyl group in acetamide and the water protons as Fig. (8). 


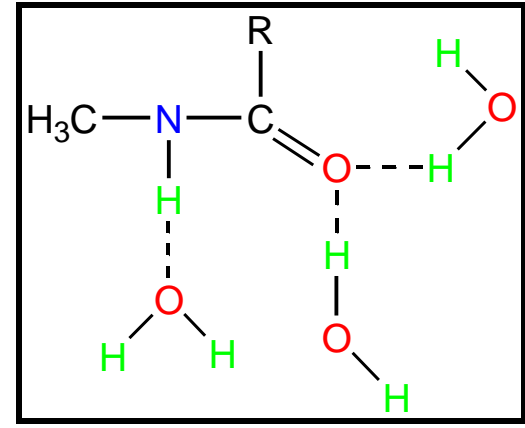

Fig. (8) Complexing of acetamide with water.

The water molecule around acetamide molecule, as a result of this complexation will absorb the heat and in the same time release of the heat which leading to decrease in the amount of liberated heat as shown in Fig. (9).

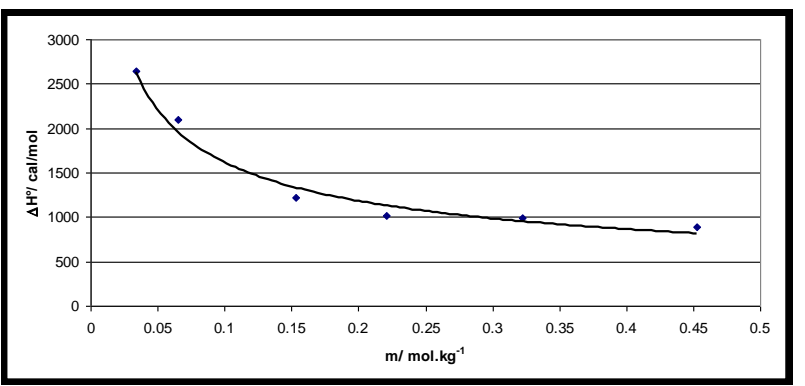

Fig.(9) System of $\mathrm{N}$ - methyacetamide + water.

\section{Table}

Values of $\varnothing_{L} / \Delta H_{s} \cdot m$ for the system $\mathrm{N}$-methyacetamide + benzene at $25^{\circ} \mathrm{C}$.

\begin{tabular}{|c||c||c||c||}
\hline $\begin{array}{c}M \\
\text { mole/kg }\end{array}$ & $\begin{array}{c}\Delta H \boldsymbol{H} \\
\text { cal/mol }\end{array}$ & $-\varnothing_{\boldsymbol{L}}$ & $\begin{array}{c}-\boldsymbol{\varnothing}_{\boldsymbol{L}} / \\
\Delta \boldsymbol{H}_{\mathbf{s}} \cdot \boldsymbol{m}\end{array}$ \\
\hline \hline 0 & 2100 & 0 & 0 \\
\hline \hline 0.0013 & 1956 & 144 & 56.6 \\
\hline 0.0018 & 1890 & 210 & 62.7 \\
\hline 0.0052 & 1422 & 678 & 91.695 \\
\hline 0.0132 & 652 & 1148 & 173.78 \\
\hline 0.0184 & 476 & 1624 & 185.6 \\
\hline 0.0252 & 323 & 1777 & 218.33 \\
\hline 0.0334 & 242 & 1858 & 229.89 \\
\hline 0.0421 & 164 & 1936 & 280.4 \\
\hline
\end{tabular}

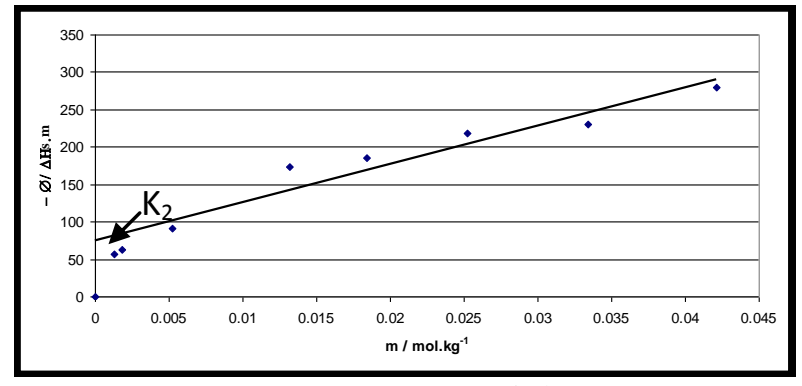

Fig.(10) Determination of dimerisation constant $k_{2}$ of $N$-methyacetamide + Benzene.

In above table and Fig. (10) are illustrated the lim it value of $m=0$ represent the constant $\mathrm{k}_{2}$ of dimerisation.

$$
\mathrm{K}_{2}=75
$$

\section{Conclusion}

Through the study on the effect of polar or non-polar solvents on $\mathrm{N}$-methyacetamide, we have observed that the difference clearly, through our observation we have found that the effect of solvent on the solute from one to another which leads different values of $\Delta \mathrm{H}$, any how the thermodynamics values which we have obtained as a result mixed of $\mathrm{N}$-methyacetamide + solvent which plays an important role in this process.

\section{References}

[1] Ghmeron. G. G. and Esslemont. G. T;" Qulitative study of copolymer of monosubstitedamide in $\mathrm{CCl}_{4}$ ". Polymer, 13, 435, 1972.

[2] Hollis. J. M; Lovas. F. J. and Kleiner "Detaction of acedtamide"; the Astrophysical. J. 643 (2), L25- L28, 2006.

[3] Carl. R.; Kemniz and mark. J. Amide Resonance correlates with Breadth of C- N Rotation. barries. J. Am. Chem.. Soc; 129. 9. 2009.

[4] Freyman. Thesis of doctorah of state.;"copmlexing study of selfassociation of N-monosubstitedamides." Paris, 1938.

[5] Chapiro. A and Perc. L.;" polymerization study of acrylamide with acry lonitrile " Europ. J. 7, 1335, 1971.

[6] Coggeshall. N. D. and Sair. E. L.; Calorimetric study of $\mathrm{N}$ - methyacrylamide in $\mathrm{CCl}_{4}$." J. Amr. Chem. Soc; 73, 5414, 1951. 
[7] Alexandera and Douglas. C.; Strength of $\mathrm{N}-\mathrm{H} . . \mathrm{O}=\mathrm{C}$ in formamide and N-methyaceta-mide". Miller of University City. Esat. Jarvi of ballwin. Jul. 29, 2008.

[8] Karl scheidt;"Amide bonding in reveso organic chemistry". Organic chemistry Nature, 465, 1020- 1022, 2010.

[9] Remijan. P. R.; Jewell. v.v, ll yushine and kliner. L. "Detection of acetamide, the largest interstellar molucle with apeptide bond. The Astrophysical. J. 643 (2), L25L28, 2006.

[10] Hunter and Lias; " Evalvated gas phase bacities and proton affinities of molecules; J. phy. Chem.. 1998.

[11] Kendill; Biochemistry, 29, 7133- 7155, 1990.

[12] Allison. S.K and Bates. S. P, J. Phy. Chem, B110- 21319- 21326. 2006.

[13] Qihn; Ping, Lu;" Molecular dynamics simulations of $\mathrm{N}$ - methylacetamide in water J. Candian of chemistry. Dece. 01, 2009.

[14] Brein.E.P.;Okamoto.Y.;"Thermodynamic perspective on the dock- lock groth mechanism of amylod". J. Phy. Chem. B, 113, 14421- 14430, 2009.

[15] Kim. J and Strab. J. E "relation ship between protin floding thermodynamic and energy landscape. Phys. Rev. E79. 030902 2009.

[16] Berezovsky. 1 and Shakhovick. E.; physics and Evolution thermophilic adaptation. PNAS. 102, 127422005.

[17] Crain. J.; Martyna. G. J." structural properties of liquid NMA, path interal and classical molecular dynamics"; J. Phy. Chem. mar. 7, 124 (9) 2006.

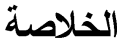

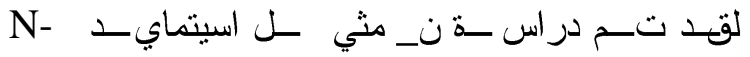

methylacetamide

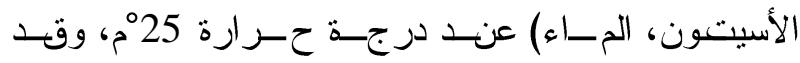

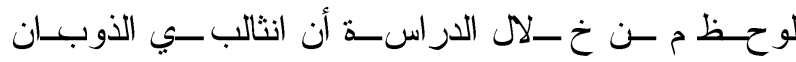
Enthalpy dissociation يعود إلى تكوين الآصرة الهيدروجينية بين جزيئات المذاب Self association

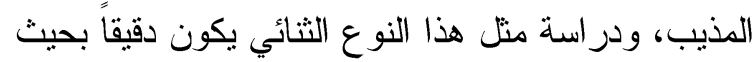

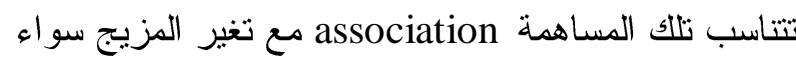
أكان المذيب قطبي أو غير قطبي. 